\title{
El carcinoma in situ y la radioterapia
}

\author{
Doctor Tewwfick Majluf \\ (Instituto de Enfermedades Neoplásicas - Lima) (1)
}

El problema del carcinoma in situ que asienta en el cuello uterino data de unos 40 a 50 años, y ha cobrado actualidad debido a dos circunstancias básicas:

$10 \mathrm{Al}$ vehemente anhelo de los cancerólogos de mejorar los resultados del tratamiento del cáncer del cuello uterino, y

2 . A la introducción del citodiagnóstico.

Hay afán por mejorar los resultados del tratamiento porque resde hace un buen número de años parece que hubiera un estancamiento en los porcentajes de supervivencia a pesar de los grandes progresos realizados en el campo de la técnica, ya sea quirúrgica o radioterápica, y de la introducción de nuevas armas terapéuticas, tales como el supervoltaje, los radioisótopos, lás substancias cancerolíticas, la endocrinología, etc. Por otra parte, el citodiagnóstico ha llamado poderosamente la atención sobre la posibilidad de descubrir lesiones malignas insospechadas en su primera fase de neoformación y de tratarias precoz y aficazmente.

Pero si el acuerdo es unánime respecto a estas circunstancias no es menos verdad que hay ciertas discrepancias en cuanto a la conducta que se debe seguir frente al carcinoma in situ. Descie el punto de vista radioterápico esta conducta depende de la respuesta que merezcan estas dos preguntas fundamentales:

10 El carcinoma in situ, ¿es o nó es un verdadero cáncer?

$2^{\circ}$ Si es un verdadero cáncer, ¿cual es, en general, el trata. miento más indicado?

(1) Reproducido de la "Revista Ginecología y Obstetricia" de Lima. Vol. I. No 2. Diciembre de 1955 . 
Respecto a la primera pregunta, el radioterapéuta necesita una respuesta firme e inequívoca ya que la radioterapia es una terapia heróica y casi tan radical como la cirugía: inutiliza el utero, destruye la función ovárica, puede provocar fibrosis de los tejidos y estrechez ureteral y vaginal. Desafortunadamente, frente a un caso particular de carcinoma in situ, no disponemos de los medios necesarios para asegurar que dicho carcinoma fuera un verdadero cáncer, o por lo menos que en su evolución seguiría inevitablemente una fase invasiva. Muchas cervicitis crónicas, muchas metaplasias, la administración de estrógenos, el embarazo (1) (3), las infecciones a virus y muy particuiarmente la tricomoniasis vaginal (2) (4), realizan cuadros microscópicos idénticos al carcinoma in situ. Se han descrito casos que no llegan a la fase invasiva, otros que han permanecido más de 12 y aún de 18 (5) (9), años sin romper la basal. Se han observado también casos reversibles, en los que las células de aspecto neoplásico han recobrado su aspecto de células normales. Más aún no hay acuerdo unánime respecto a si el carcinoma en su fase invasiva ha tenido su origen en el mismo carcinoma in situ o si ha desarrollado en otro foco independiente. Tampoco hay acuerdo respecto a la extensión que debe tener para que merezca calificarse como un carcinoma in situ. (6)

En el caso de que se pueda llegar a la conclusión de que el carcinoma in situ es un verdadero cáncer en su fase preinvasiva, la respuesta a la segunda pregunta es, para el radioterapeuta, bastante sencilla: si dicha lesión es un cáncer, entonces está demostrado, universalmente, que el tratamiento de elección para el cáncer del cuello uterino es el tratamiento radioterápico. La mayoría de los ginecólogos, sin embargo, se inclinan por el trata. miento quirúrgico merced a los siguientes argumentos:

10 La cirugía presenta la ventaja de poder extirpar, al mismo tiempo que el foco neoplásico, todos los órganos susceptibles de sufrir a la larga, degeneración cancerosa, inclusive los ovarios.

20 Aplicando las técnicas de la conización o de la amputa. ción del cuello la cirugía permite conservar, en las mujeres jóvenes, tanto el útero como los ovarios cuando ei embarazo es de importancia decisiva en la vida de la paciente.

30 El tratamiento quirúrgico es rápido y expeditivo.

4 o Nos permitiría obtener piezas operatorias completas para estudio seriado, y por consiguiente, un conocimiento más profundo de la historia natural del carcinoma in situ. 
El primer argumento, que es evidentemente, el más fuerte se justifica solamente en algunos casos, ya que la manifestación de neoplasias malignas independientes en los órganos que se conservan es muy rara. Los estudios sobre carcinomas múltiples han demostrado que la probabilidad de que una persona sufra la neoformación de dos o más cánceres en órganos distintos, es la misma que tiene una persona tomada al azar, de albergar un solo cáncer. Es decir, que un canceroso no está más predispuesto que una persona cualquiera tomada de la población general, a desarrollar un nuevo cáncer (7). Por consiguiente no sería lógico so. meter la mayoría de los casos a un tratamiento radical indicado solamente para los casos raros, porque de prevalecer este criterio, se tendrían que operar radicalmente todas las neoplasias del aparato genital femenino y abandonar por completo el tratamiento radioterápico en los casos que tengan la menor posibilicad quirúrgica cosa que no se admite ni por los ginecólogos más radicalistas. El mejor tratamiento del cáncer del cuello uterino es todavía el radioterápico y, con mayor razón, debería aplicarse al carcinoma in situ, a donde es de esperar curas definitivas en el $100 \%$ de los casos, por lo menos teóricamente.

Las pocas instancias de fracasos publicados se deben muy probablemente, a deficiencias en el manejo de radium (10) o a la muy improbable posibilidad de la existencia de casos radioresistentes.

El segundo argumento, lo mismo que el primero, se aplica solamente a casos muy especiales. El carcinoma in situ se presenta en mujeres cuya edad se avecina a los cuarenta años (2), es decir, cuando la función ovárica se aproxima a su decadencia y que el interés por conservar los ovarios es menor que el de no correr el riesgo de tener un cáncer. Más las conizaciones y las amputaciones del cuello no son operaciones perfectas: dejan mucho lugar a las recidivas y no siempre queda el útero en condiciones favorables para el embarazo (8). Por otra parte, es extremadamente crecido el número de ginecólogos que no son partidarios de conservar ni el útero ni los ovarios.

Considerando la rapidez en el tratamiento la radioterapia no representa ninguna desventaja con respecto a la cirugía. En el tratamiento del carcinoma invasivo del cuello se requieren 5 a 6 semanas debido a una integración indispensable de la curie. terapia con la roentgenterapia; pero en el caso del carcinoma in situ, ello sería de una semana solamente, ya que la apiica- 
ción de radium uterovaginal, prescindiendo de la roentgenterapia profunda, sería ampliamente suficiente si el agente radífero es manejado en forma adecuada.

En cuanto a la obtención de material patológico para estudio, éste se podría obtener en forma muy aceptable mediante biopsias repetidas, exámenes post-mortelm, piezas operatorias eventuales y experimentación animal.

Toda esta argumentación se aplica, claro está, al problema ael carcinoma in situ desde el punto de vista general. Tratándose de casos particulares no hay duda alguna de que tanto la cirugía como la radioterapia tienen cada una sus indicaciones absolutas. La cirugía está indicada, por ejemplo, en casos de manifiesta tendencia hereditaria hacia la formación de cánceres del aparato genital o múltiples; en los casos en los cuales el interés por conservar la función reproductiva es preponderante; en los casos que representan otros focos independientes a nivel del endometrio y en los que se compruebe evidente radioresistencia. La radioterapia tendría su indicación absoluta en casos de alto riesgo quirúrgico, o cuando la operación quirúrgica es rechazada.

Creo que esta es la manera como el radioterapeuta debe afron. tar el carcinoma in situ para decidir según las circunstancias, a la luz de estos postulados, hasta que se haya obtenido una visión más clara de todo el problema en su conjunto.

\section{BIBLIOGRAFIA}

1. SCHLELFSTEIN, J.- "Changes in the Uterine Cervix Associated with Pregnancy", New York State J. Med. 50: 2795-2801. 1950.

2. SCAPIER, J.- "Intraepithelial Carcinoma of the Cervix"; a cytohistological and clinical Study, cáncer, 5 2-315. 1952.

3. NOVAK, E.-“'The Pathological Diagnosis of Early Cervical and Corporeal Cancer with Special Reference to the Differentiation from Pseudomalignant inflamatory lesions". Am. J. Obs. Gyn. 18: 449-417. 1929.

4. DARO, A. et al.- "Post-partum Cervical Carcinoma". Am. J. Ob. Gyn. 67: 1. 15. 1954.

5. HUEY, Th, et al.-Preinvasive Carcinoma of the Cervix". Am. J. Ob. Gyn. 68: 761. 1954.

6. REAGAN, W. J.- “The Citological Diagnosis of Carcinoma in Situ". Cancer 4: 2-255. 1951.

7. WATSON, T. A.-“Cáncer". 6: 2-365-371, march. 1953.

8. Cervical Carcinoma in "Queries and Minor Notes". J. A. M. A. 142: 13 1035, april 1. 1950.

9. GALVIN, G. A. y Col-_"Clinical Relationship of Carcinoma in Situ and Invasive Carcinoma of the Cervix". J. A. M. A., 149: 8-744, june 21. 1952.

10. PUND, E. R. and AUERBACH, S.- "Preinvasive Carcinoma of the Cervix". J. A. M. A. 131: 12-960, july 20. 1946. 